\title{
Intellectual Property Protection as Strategic Trade Policy
}

\author{
James A. Brander ${ }^{\mathrm{a}^{*}}$ \\ ${ }^{a}$ University of British Columbia
}

\begin{abstract}
Despite the WTO agreement on Trade Related Intellectual Property Rights implemented in 1995, international coordination of intellectual property (IP) policy remains contentious. This paper reviews recent research addressing whether IP policy should be standardized across countries, and whether IP protection has become overly cumbersome. It concludes that much IP protection is excessive (possibly reflecting regulatory "capture") and that international standardization has regressive redistributive effects and unclear efficiency effects. Coordinated decentralization would be preferred. It also suggests that much intellectual property protection can be viewed as "strategic trade policy" whose primary effect is "profit-shifting" rather than the enhancement of economic efficiency.
\end{abstract}

JEL Classification: O34, F12, F5

Keywords: intellectual property, strategic trade policy

\section{Introduction}

Innovation is essential for continuing improvement in living standards and perhaps even for mere sustainability ${ }^{1}$ of current standards. Such innovation is strongly affected by the economic environment surrounding innovators and intellectual property (IP)

* Sauder School of Business, University of British Columbia, Vancouver, BC V6T 1Z2, Canada. Tel: 604822 8483. E-mail: brander@sauder.ubc.ca. An earlier version of this paper was the keynote address at the 2007 Asia-Pacific Journal of Accounting and Economics (APJAE) Symposium on Strategic Trade Theory and Economic Development. The author thanks Hong Hwang and Eden Yu for the invitation to deliver the keynote address and for helpful comments. The author is also grateful for the comments of Larry Qiu and other symposium participants, and of Werner Antweiler, Edward Egan, Keith Head, Thomas Hellmann, and Barbara Spencer. Financial support from SSHRC MCRI grant 412-98-0025 and from the Maurice Young Centre for Entrepreneurship is gratefully acknowledged.

${ }^{1}$ For a recent discussion of the role of technological progress in the "sustainability" debate see Brander (2007). It seems likely that the combination of still-rapidly increasing population and continuing resource depletion means that significant technological progress is required just to offset the welfare effects of declining natural resources per capita. 
policy is an important part of this environment. Economists have long been interested in policy toward IP, particularly patent policy, although other areas of IP policy, such as copyright and trademark protection, have also received significant attention. Most of the early work on IP dealt with a closed economy setting. However, in recent years, it has become increasingly clear that international aspects of IP policy are of central importance. Despite the World Trade Organization (WTO) agreement on trade-related intellectual property rights (TRIPs) that went into effect in 1995, it has been difficult to achieve international consensus on an appropriate international regime for intellectual property protection.

This paper reviews recent research addressing whether IP policy should be standardized across countries, and whether IP protection has become overly cumbersome. It provides a simple unifying theoretical structure within which the major themes in the relevant literature can be demonstrated. It also suggests that much IP protection can be given a "strategic trade policy" interpretation as recent extensions of IP policy apparently serve primarily to shift profits (and other rents) between countries rather to enhance efficiency.

In considering the extent to which IP protection should be harmonized or standardized across countries it is useful to focus on three specific levels of harmonization. One level would be strict uniformity or standardization of IP policy. A second level can be referred to as "cooperative decentralization" or "coordinated decentralization" under which different countries could adopt different intellectual property standards, subject to general agreement about acceptable variation and subject to some level of international control and coordination. The final level is non-cooperative decentralization, in which each country sets its policy unilaterally. The conclusion reached is that economic principles and relevant evidence favor the second of these options cooperative or coordinated decentralization, rather than standardization. With respect to the overall level of intellectual property protection, the weight of recent evidence suggests that such protection has become excessive, particularly from the point of view of low income countries.

One puzzle concerns why increasing standardization appears to be a major force at the political level given what is taken in this paper to be the weight of economic analysis, which seems to favor weaker aggregate IP protection and increased decentralization. One possibility is that the policy authorities and political "champions" for stronger and more uniform IP protection are strongly influenced by the relatively small group who gain the most from increased and more uniform IP protection. In short, the "capture" theory of regulation, first clearly articulated by Stigler (1971), might have considerable relevance for the international IP policy regime.

Section 2 provides some examples of recent controversies that have arisen in the IP area. Section 3 reviews and formalizes the foundations of IP policy in a domestic context, including what is referred to as the "fundamental trade-off" of IP policy. Section 4 extends the review and the simple formalization to address international considerations. Section 5 contains the outline of a formal representation of IP policy as strategic trade policy. Section 6 provides an overview of the empirical evidence relevant to the issues raised in preceding sections. Section 7 is devoted to concluding remarks. 


\section{Examples of IP Policy Issues}

\subsection{Current US Complaints About Chinese IP Protection}

In April of 2007, the United States filed two WTO intellectual property actions against China. One case is based on an assertion of inadequate enforcement of IP policy. While acknowledging that Chinese law recognizes protection of intellectual property in principle, the complaint asserts that Chinese law, as currently implemented, creates large loopholes or "safe harbors" for violation of trademarks and copyrights. The second case seeks removal of Chinese import and internal distribution controls that prevent US and other foreign distribution networks from operating in China. In effect, the US argues that legitimate distributors are prevented by Chinese policy from competing with counterfeiters and "pirates" operating in China. Also in April of 2007, the United States issued a statement of concern about Chinese failure to enforce pharmaceutical patents. ${ }^{2}$ The primary concern expressed by the US Trade Representative in the WTO cases is that "[i] nadequate protection of intellectual property rights in China costs US firms and workers billions of dollars each year...".

These concerns illustrate several important points. The first point concerns the primacy of profit-shifting concerns. No attempt is made to disguise the central concern of the US policy authorities regarding increasing returns to American producers. A second point concerns the role of standardization. At present, incentives in China and elsewhere to copy patented products, copyrighted products, and infringe trademarks reflect the very strong levels of IP protection imposed on the legal use of this IP in the US.

This paper argues that it would be preferable for countries like China not to adopt that same level of IP protection as the US. For example, with respect to pharmaceuticals, it has been argued that a much shorter period of patent protection than the current 20 year period would enhance efficiency, and that relatively rigorous compulsory licensing requirements would also be appropriate. These arguments have received considerable emphasis with respect to drugs used to treat HIV. A shorter patent period and more favorable licensing requirements would greatly reduce the incentives for unauthorized use of intellectual property. Most economists would be sympathetic to the second of the US WTO complaints - that US and other foreign distributors should have freer access to Chinese markets. This is more a matter of trade liberalization than of IP protection, but it does have significant implications for IP protection.

${ }^{2}$ The WTO actions are described in a United States Trade Representative (USTR) Press Release of 9 April 2007. The concerns about pharmaceutical patents are contained in a USTR press release of 30 April 2007 (The "Special 301 Report"). Both press releases were accessed on the USTR website in May 2007 at http:// www.ustr.gov by following the "Press Room" link. 


\section{2. "Patent Trolls" and the BlackBerry Case}

Quite a few users of the US patent system are firms and individuals, often referred to as "patent trolls", ${ }^{3}$ who do little if any innovation and have no serious plan to ever produce anything but who acquire patent rights of marginal (or sub-marginal) technical relevance to the activities of active firms. These patent trolls can threaten to use patent-related litigation to disrupt active firms, who often find it easier to pay off such claims rather than incurring the expense and disruption of extensive litigation. By threatening such disruptions, these opportunistic patent trolls seek to obtain transfers or "rents" from genuine innovators. One recent case involved Research In Motion (RIM) Ltd of Canada, the producer of "BlackBerry" e-mail and cell phone services. It recently (February 2006) paid US\$612.5 million to a small Virginia-based firm, NTP. The patents held by NTP were of very questionable merit and were likely to be disallowed by the US Patent Office. However, NTP used sympathetic local courts in Virginia to threaten RIM with significant disruption and obtained a large settlement that many observers view as wholly unjustified.

Large producers in biotechnology, information technology, and other innovationintensive areas now expect to maintain significant legal teams to do nothing but litigate and negotiate patent and other IP claims. Such activity acts as a tax on innovative activity and is a significant disincentive for innovation. It also indicates a shift in resources away from production of wealth (i.e. research and development) to fighting over the distribution of existing wealth (i.e. to transfer-seeking through the legal system). The BlackBerry case illustrates the patent troll problem very effectively. In addition, it illustrates the disadvantage that a foreign firm (in this case a Canadian firm) might have when contending with IP cases brought by plaintiffs in the US who engage in courtroom shopping - seeking the most favorable jurisdiction in which to file a case.

\subsection{Obvious Innovations: One-Click Shopping}

A complaint frequently leveled at the US patent system is that it is just too easy to get patents. One criterion for receiving a patent is that the innovation not be "obvious", but some recent decisions by the US Patent and Trademark Office imply a very low standard on this criterion. Perhaps the best-known case involving "obviousness" is the Amazon.com "one-click shopping" patent, granted in 1999. Amazon.com is a pioneer in online sales of books and other products. The patent describes the idea of allowing a customer to click a single icon that brings together the credit card number and address of the (registered) customer with product information, essentially reducing the primary purchase transaction to a single click. About three weeks after receiving the patent Amazon brought a suit against Barnes and Noble, another online bookseller offering a one-click sales option to customers.

${ }^{3}$ Trolls are imaginary creatures that frequently appear in European fairy tales. Trolls are normally large, strong, and unpleasant and engage in a variety of undesirable activities. One common practice among trolls is to sit at a bridge or a mountain pass and force travelers to pay a toll before allowing them to pass. This extortion is viewed by some as similar to the strategy of firms that acquire patents so as to pursue lawsuits rather than to produce a product. 
The Amazon suit created considerable controversy, including boycotts against Amazon. In light of the large amount of negative publicity, Amazon reached a settlement with Barnes and Noble that was believed to impose little cost on Barnes and Noble. Amazon has not brought any additional suits against internet vendors despite the widespread use of "one-click shopping". Many observers, including Amazon programmers, expressed surprise that something as obvious as one-click shopping could be granted a patent. Other users of one-click shopping methods who, arguably, pre-dated Amazon.com, did not apply for a patent because it seemed so obvious. After all, many things on the internet are done with a single click and, presumably, making any internet transaction as simple as possible is an obvious objective. In an April 2007 decision (KSR International v Teleflex) the Supreme Court of the United States found that the standard being used by lower courts for deciding on whether an innovation was "obvious" was too generous to patent applicants.

These cases are interesting because they illustrate the level of IP protection that has been sought by the US in seeking to standardize IP protection in different countries. More broadly, there is also concern about decisions in the US to allow patents for software (otherwise covered by copyright), business methods, and the genetic code of living animals. To many observers it seems unlikely that such levels of IP protection makes sense even for the US on a purely domestic basis. It is even more unlikely that such a standard would be appropriate for countries like China or India.

The reach of holders of US IP rights has been reduced by another recent US Supreme Court decision. In a 1 May 2007 decision (Microsoft v AT\&T) the Supreme Court ruled that AT\&T could not sue Microsoft over alleged patent infringement incorporated in software produced and sold outside of the US. In other words, the Court reasserted the principle that US IP law cannot be applied on an extraterritorial basis.

These examples of IP policy all involve the US, reflecting the primacy of the US as the world's major producer and exporter of IP. Furthermore, they raise concerns that the level of IP protection in the US has risen too high, and they illustrate problems in applying such standards to other countries. Interestingly, after decades of increasing IP protection in the US and increasing extension of US IP standards to the rest of world, in the first few months of 2007, the Supreme Court of the United States seems to have initiated what might be a turning point with respect to both trends.

\section{Foundations of Intellectual Property Policy}

\subsection{The Fundamental Trade-off of IP Policy}

The modern literature on innovation and intellectual property can be traced back at least as far as Arrow (1962), who asked whether a monopolist or a competitive firm (who could become a monopolist with a successful patent-protected innovation) would have a stronger incentive to innovate. Arrow also asked whether either market structure would give rise to full efficiency. The answer, in the standard case, is that the monopolist has a weaker incentive to innovate than a competitive firm as a monopolist would be held back to the extent that the innovation would "cannibalize" pre-innovation monopoly profits. The monopolist therefore has an incentive to "rest on its laurels", as is consistent with the 
observation of John Hicks that "the best of all monopoly profits is a quiet life". However, neither the monopolist nor the competitive firm undertakes as much innovation as would be implied by a "first-best" world, even with a perfectly-enforced infinitely-lived patent.

The difficulty in achieving "first-best" efficiency is that, in the absence of perfect price discrimination and full property rights, the innovator cannot capture the full social benefits of the innovation and therefore does not set the full social marginal benefit equal to the marginal cost of innovation. A divergence between social and private benefits to innovation arises in part from the public good aspect of knowledge (or "intellectual property"). Once knowledge (such as how to make an effective medication) is discovered, it can be transmitted at very low cost and it is difficult to keep the knowledge exclusive. Without intellectual property rights, it is therefore hard for the innovator to get a return on "production" of this knowledge as other potential users can acquire it without compensating the innovator. The innovator would therefore have inefficiently weak incentives for innovation. In addition, a given innovation might have positive externalities in providing useful input to other innovations. Also, even without externalities or public good issues, a dynamic market failure would arise simply because much of the benefit of innovation accrues to consumers in the form of consumer surplus that cannot be appropriated by the innovator.

Without incentive and informational constraints a "social planner" with full information and complete powers of calculation and compulsion could simply instruct innovators to undertake the first-best level of innovation. However, the first-best level of innovation is not feasible in any model with plausible incentive and information constraints. Innovators cannot simply be "instructed" to provide the first-best level of innovation. They must be given incentives. Attention shifts to the "second best" or constrained optimum that recognizes a fundamental incentive-based tradeoff. This fundamental tradeoff can be thought of as a trade-off between "static efficiency" and "dynamic efficiency".

Creating incentives to innovate in turn creates an apparently unavoidable static efficiency cost. Specifically, a patent (or other type of intellectual property right) allows the holder to exercise at least partial monopoly power over the innovation, creating static inefficiency. A stronger intellectual property right would presumably increase the incentive to innovate, but at the cost of greater inefficiency due to market power. Getting this trade-off just right is the challenge at the heart of IP policy. The policy variable is the strength of the intellectual property right (IPR).

In practice, the strength of the IPR is determined by a variety of factors. In the case of patents, the most obvious variable is the length of the patent (which is now 20 years for most innovations in most jurisdictions). However, patent breadth is also very important. A narrow patent allows limited monopoly power as it would not preclude closely related innovations that would provide close substitutes in the product market. A broad patent provides more extensive monopoly power. The difficulty in getting patents approved is also relevant, as is the level and nature of enforcement. In addition the nature and extent of compulsory licensing requirements, situations under which patents maybe terminated, and various other factors are also relevant. Thus IPR strength is multi-dimensional. However, most early work on IP represents the strength of IP by a scalar variable, typically the length of a patent. 
The first well-known formal analysis of the trade-off between static inefficiency due to market power and dynamic inefficiency due to sub-optimal innovation is Nordhaus (1969) (as further clarified in Scherer (1972) and Nordhaus (1972)). Nordhaus (1969) considers a firm that can undertake a small cost-reducing innovation in an otherwise perfectly competitive market. If the innovation is sufficiently modest, the firm will displace competitive production but leave the price unchanged, earning above-normal profits arising from the difference between the price and its new (reduced) marginal cost, for the period of the patent. After the patent expires, there is competitive entry and price falls to the new (lower) marginal cost. The amount of cost-reduction depends on the investment devoted to innovation, and this investment process has decreasing marginal returns. The policy variable is patent length. The potential profit and hence the incentive to innovate and amount of innovation depend on the length of the patent. Based on this structure it is possible to solve for the optimal patent length. Valuable textbook treatments of the basic issues associated with IP are provided by Scotchmer (2004) and Tirole (1988, Ch 10).

\subsection{A Simple Reduced-Form Treatment of the Fundamental Trade-off}

A single innovating firm that earns profit $\pi$ can be considered. This profit depends on the extent of IP protection. For these purposes, it is helpful to note that there would be a relationship between the innovator profit, $\pi^{I}$, and the level of IP protection, denoted here as $\alpha$. As is consistent with Nordhaus (1969), it is assumed that $\pi^{I}$ is strictly increasing in $\alpha$ over the relevant range of $\alpha$. Letting subscript $\alpha$ denote a derivative,

$$
\pi^{I}=\pi^{I}(\alpha) \text { where } \pi_{\alpha}^{I}>0
$$

This is slightly more abstract (and simpler) than the analysis of Nordhaus (1969), but has the advantage of greater generality as it can be interpreted as including either product innovation or process innovation, whereas as Nordhaus deals just with process (i.e. cost-reducing) innovation. Also, this formalization can implicitly reflect any kind of IP protection, not just patent length, taking $\alpha$ as an index reflecting the combined effect of patent length, patent breadth, patent enforcement, and other aspects of IP protection.

Consumers might also get consumer surplus, $C S(\alpha)$, from innovation undertaken by the firm. Surplus is not monotonic in $\alpha$ over the relevant range. At low levels of $\alpha$ one would expect consumer surplus to be increasing in $\alpha$. At the extreme, a very low level of $\alpha$ might preclude innovation altogether. An increase in $\alpha$ would then induce innovation and generate gains to both the innovator and to consumers. However, at sufficiently high levels of $\alpha$, the increasing market power granted to the innovator would come at some cost to consumers. Therefore, $C S$ would decrease in $\alpha$ after some level.

$$
C S=C S(\alpha)
$$

where $C S^{\prime}(0)>0 ; C S^{\prime \prime}(\alpha)<0$; and

$$
C S^{\prime}(\alpha)<0 \text { for sufficiently large } \alpha \text {. }
$$


There are also other firms to consider. One possibility which should be allowed for is that other firms might earn profits. Possibly these might be firms that could license the innovation and then compete with the innovator in an oligopoly market, or possibly potential oligopolistic rivals might enter without paying license fees once the patent expired. Their profit is denoted as $\pi^{R}$ (where $R$ stands for "rival"). This profit of other firms would have a similar shape to consumer surplus - first rising in $\alpha$ and then falling. $S$ is defined as combined surplus of consumers and other firms.

$$
S(\alpha)=C S(\alpha)+\pi^{R}(\alpha)
$$

This very simple structure captures important aspects of much analysis of IP. $\pi^{I}$ and $S$ can be interpreted as being expected present values, so neither uncertainty nor dynamics are excluded by the analysis, although there is no further explicit consideration of such issues here. National welfare, $V$, is given by the sum of innovator profit and national surplus.

$$
V(\alpha)=\pi^{I}(\alpha)+S(\alpha)
$$

A national government that wished to maximize national welfare would set $d V / d \alpha$ to zero, so the first order condition for an optimum would occur where

$$
\pi^{\prime}(\alpha)=-S^{\prime}(\alpha)
$$

It follows that marginal surplus must be negative at the solution. Thus, the optimum requires setting $\alpha$ such that the (positive) marginal profit associated with additional IP protection is just offset by the marginal decline in surplus. The logic is clear. Small increases in $\alpha$ from a very low level would increase innovation and increase both profit and surplus. Further increases in $\alpha$ would raise welfare for all parties up to a point at which the increased monopoly power of the firm (created by IP protection) would lead to sufficiently high prices for a sufficiently long time so that the extracted surplus from consumers (and other firms) would begin to offset the gains from innovation. The solution is illustrated in Figure 1.

\section{Figure 1: A second-best intellectual property policy}

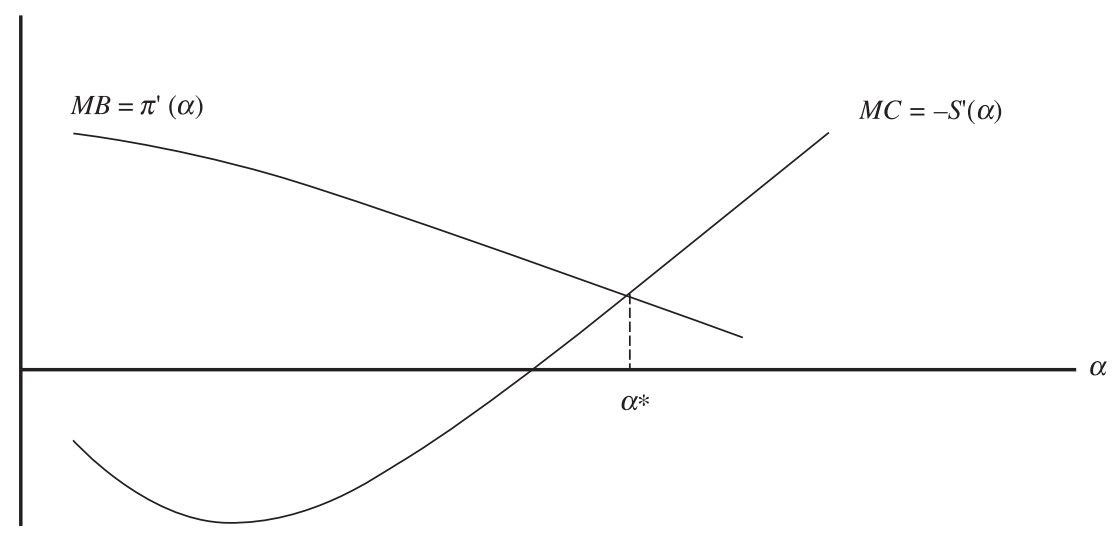


The early work on patents creates two important presumptions. One is that innovation tends to be too low relative to the first best or fully efficient allocation. The second best or constrained optimum might be the best that can be done, but it still results in an undersupply of innovation. This creates a predisposition in favor of measures that increase investment in innovation. A second presumption is that increases in intellectual property protection increase investment in innovation. A basic property of the models of Nordhaus and most others is that innovation is increasing in the measure of IP protection considered (typically patent life).

It is important to recognize that neither of these presumptions can be taken for granted in practice. In addition to the incentives for innovation created by patents and other IP protection, research is heavily subsidized. In particular, there is an enormous subsidy to research through the funding of universities. Furthermore, this subsidy increasingly flows through to the private sector due to increasing university-based efforts to transfer technology to the marketplace and receive commensurate financial rewards. In addition, there are various subsidies and tax concessions to research and development (R\&D) in the private sector, and there is a significant subsidy to the financing of innovation (as described, for example, in Brander, Egan and Hellmann (2007)). Furthermore, such subsidies are becoming increasingly common around the world, and have a long history in North America and Europe. Once all of these measures are taken together it is far from obvious that the incentive to innovate falls short of the "first-best" level. ${ }^{4}$

In addition, following the line of research pioneered by Arrow (1962) many researchers have addressed the role of market structure in affecting innovation and the consequent interaction between intellectual property protection and market structure, including the analysis of "patent races". Classic work on this topic includes Loury (1979), Reinganum (1982), and Harris and Vickers (1985). Under some circumstances a "patent race" can induce excessive investment in innovation and excessively early implementation of innovations in an effort to pre-empt others. Such patent races constitute a second factor that might lead to excessive rather than insufficient investment in innovation.

The second presumption - that stronger IP protection gives rise to more innovation is also far from obvious. The basic point is that providing stronger protection of existing technologies can make it harder to generate new technologies. For example, as has been described by Murray and Stern (2007), a possible dynamic inefficiency of this type can result from patent policy. Specifically, if patent policy is strengthened by allowing broader scope, easier enforcement, or longer time horizons for patents, this might inhibit further research in the affected area because it makes it more difficult for other innovators to use their potential innovations. There are, in particular, a number of specific cases in which owners of patents have used that ownership to suppress rather than encourage innovation. (See Dunford (1987) for a description of classic examples of this practice.) This concern is consistent with the analysis of Yiannaka and Fulton (2006) who find that US firms often use excessive patent breadth to deter entry by competitors. This highlights an inefficient use of the patent system, as excessive patent breadth may leave innovations

\footnotetext{
${ }^{4}$ Much public debate seems to be based on the incorrect premise that more innovation is always better. Economists understand, of course, that there is an efficient level of investment in innovation and that it is quite possible in principle to exceed this level.
} 
under-commercialized. Jaffe and Lerner (2004) also emphasize the point that recent changes strengthening US patent policy have substantially increased the cost of research due to fears of litigation and have induced many smaller enterprises to abandon $R \& D$ efforts.

\subsection{The Capture Hypothesis}

The possibility that public policy might be determined in large part by the selfinterest of policy-makers and those in a position to influence policy has a long tradition in economics. This private interest approach to policy is sometimes referred to as the "positive theory of regulation" or the "capture hypothesis". The analysis of international trade policy, in particular, has emphasized that trade barriers are more readily explained by special interests that "capture" the policy process rather than by a normative theory of policy. This paper will not try to review the very large literature on this view of public policy here, except to note the classic article by Stigler (1971).

This "capture" view of policy has received relatively little study in the context of IP, even though it would seem to be a very important area of application. This question is explicitly addressed by Boldrin and Levine (2004) and some of the issues are touched upon by Anton and Yao (1994). This general theme is also important in Jaffe and Lerner (2004). At a formal level, it is easy to model the possibility that the innovating firm might partially capture the IP policy agenda. If so, government decision-making would place reduced weight on consumer surplus, giving rise to a policy objective function of the form

$$
G=\pi(\alpha)+\beta S(\alpha) \text { where } 0 \leq \beta \leq 1
$$

At one extreme, where $\beta=0$, policy authorities would place no weight on consumer surplus at all, and would seek to maximize the firm's profit. This would be the case of complete capture. At the other extreme, where $\beta=1$, the policy authorities maximize national welfare, as given by (5).

From the assumptions made so far it follows easily that partial capture $(\beta<1)$ of the policy authorities leads to an inefficiently high level of IP protection. This can be illustrated in Figure 1 by replacing the marginal cost curve $-S^{\prime}(\alpha)$ with $-\beta S^{\prime}(\alpha)$. This curve would be lower than $S^{\prime}(\alpha)$ in the relevant quadrant and would give rise to a higher (and hence inefficient) level of IP protection, $\alpha$.

\section{International Protection of Intellectual Property}

\subsection{The Literature}

The international aspects of IP protection have generated notable academic interest at least since the early 1990s. Early papers of particular interest are Chin and Grossman (1990), Deardorff (1992), and Helpman (1993). All three of these papers ask a similar question - if patent protection is extended from the "North" (where innovation occurs) to the "South" (where innovation does not occur), what are the distributional and efficiency 
(or world welfare) consequences? These three papers are based on quite different models, but all three give essentially the same answer. A wide range of outcomes are possible depending on model details and parameter values, but extending patent protection to the South normally lowers welfare in the South, increases welfare in the North and might either raise or lower world welfare. In short, these papers offer little support for expansion of IPRs to low income countries. The distributional consequences are almost certainly regressive and there is no presumption of net efficiency gains, even if the North starts out with efficient (second-best) patent policy.

One partially opposing argument is provided by Diwan and Rodrick (1991), who introduce a consideration absent from the papers discussed in the previous paragraph. Specifically, Diwan and Rodrick (1991) introduce differences in preferences between North and South. In the absence of IP protection in the South, innovators in the North focus on innovations most desired by the Northern consumers. If IP protection is introduced or enhanced in the South, this gives Northern innovators an incentive to provide innovations more suited to the South. Thus Southern IP protection is more inclined to have a positive effect on the South in the Diwan/Rodrick model than in the three papers previously mentioned.

The key questions arising from Diwan and Rodrick (1991) are empirical - how empirically significant are the relevant preference differences between North and South, and how responsive are Northern innovators to changes in the Southern property rights? The example they offer relates to music (which, incidentally, is covered by copyright, not by patents). "Northern entertainers spend resources on rock music, while Southern consumers may prefer local music". If copyright is extended in the South, this would presumably give Northern songwriters and composers a stronger incentive to produce music preferred in the South. This example is far from compelling. The image of American rock stars turning their attention to the indigenous music of various low income countries is more amusing than persuasive, although there are a few such examples. A potentially more important example might be something like a possible increase in investment in anti-Malarial pharmaceuticals if patent protection in Africa and South Asia were stronger. This author personally doubts that such effects would be strong, and suspects that the redistributional effects would be large compared to any efficiency gains - but this is certainly an open question.

More recently, two important papers have addressed the harmonization problem more directly. These papers are Lai and Qiu (2003) and Grossman and Lai (2004). In both papers different countries (which might be called North and South) can innovate, although possibly with different levels of intensity, and the two countries have various other asymmetries. Both papers compare the non-cooperative outcome in patent policy (or IPR protection more broadly) with the outcome that would arise from agreement.

Grossman and Lai (2004) also explicitly ask whether the efficient outcome involves standardization of IPR protection or variation across countries. They provide clear answers to these questions. The initial non-cooperative (Nash) equilibrium in IP protection yields (not surprisingly) different levels of IP protection in different countries. Furthermore, the level of IP protection is inefficiently low because each country has an incentive to "free-ride" on the innovative activity in the other country. An efficient agreement would raise IP protection. However, standardization of IP protection would not be expected at 
the optimum. It might occur, but it would be a coincidence. Thus, the efficient agreement would typically call for different levels of IP protection in different countries.

Lai and Qiu (2003) obtain similar results, also noting that a non-cooperative Nash equilibrium in IP protection would generate different IP protection in different countries. Specifically, the low-innovation South would have an inefficiently low IP standard due to the free-rider externality. Lai and Qiu (2003) then ask whether there would be efficiency gains if the South adopts the Northern standard. The answer is that the South would lose but the North would gain more than the South loses, so there would be efficiency gains overall. Lai and Qiu (2003) then suggest that linking IP standardization to other policies that would advantage the South (such as relevant trade liberalization) would be an appropriate response. They conclude that TRIPs taken by itself was probably a bad agreement for the South in that the South gave up "too much". (See also Lai and Qiu (2004).)

\subsection{A Formal Representation of Standardization}

To illustrate formally the key points of the international IP literature, this paper will now consider a second country and possible trade between the two countries, referred to as country $A$, which is the innovating country, and country $B$, which is the other country.

World welfare is now given by:

$$
W\left(\alpha^{A}, \alpha^{B}\right)=\pi^{A A}\left(\alpha^{A}, \alpha^{B}\right)+\pi^{A B}\left(\alpha^{A}, \alpha^{B}\right)+S^{A}\left(\alpha^{A}, \alpha^{B}\right)+S^{B}\left(\alpha^{A}, \alpha^{B}\right)
$$

where $\alpha^{A}$ is the IP standard in country $A$ and $\alpha^{B}$ is the IP standard adopted in country $B . \pi^{A A}$ is the profit earning by the innovating firm in country $A$, and $\pi^{A B}$ is the profit it earns in country $B$. Note that the profit earned in country $A$ depends on the IP standard in both countries. The other country's IP standard will have an impact of the amount of innovation done by the firm, which will affect its profit in its home market, as well as its profit in the foreign market.

The first question asked is what would happen if the IP standard were uniform, so that $\alpha=\alpha^{A}=\alpha^{B}$, and if the first country could unilaterally set this common IP standard. The objective function of the domestic policy authority can then be written as

$$
G=\pi^{A A}(\alpha)+\pi^{A B}(\alpha)+\beta S(\alpha)
$$

By comparing (8) and (9) it follows easily that, under standard regularity conditions, country $A$ would set an inefficiently high IP standard (i.e. a standard higher than the world welfare-maximizing level) if it could set the standard unilaterally. In a domestic context, the level of IP protection involves a tradeoff between the profit gains from increased IP protection and the losses in consumer surplus (and surplus of other firms) from additional monopoly power associated with increased IP protection. In an international context, the domestic government has an incentive to ignore the effect of increasing IP protection in reducing foreign consumer surplus. The natural presumption is that, if an innovating country could set the international IP standard, the standard it would set would be too strict. This is true even if the motivation of the domestic policy authority is strictly normative in the sense that $\beta=1$. Furthermore, the extent of the inefficiency increases as the extent 
of capture increases (i.e. as $\beta$ falls). In other words, "capture" of policy authorities further increases the distortion.

The structure of this problem also clearly illustrates another important point. Asymmetries between the two countries make it unlikely that the maximization of (8) with respect to $\alpha^{A}$ and $\alpha^{B}$ would yield $\alpha^{A}=\alpha^{B}$. Allowing $\alpha^{A}$ and $\alpha^{B}$ to be different (i.e. to have coordinated decentralization) weakly dominates requiring standardization and, apart from remarkable coincidence, would strictly dominate standardization. This applies even if $\beta=1$ and applies even more strongly if $\beta<1$.

The other level of harmonization discussed in the introduction is non-cooperative decentralization - the complete absence of harmonization. Once again, it is clear the coordinated decentralization must dominate non-cooperative decentralization. However, non-cooperative decentralization and standardization cannot be ranked. It can also be asked what effect moving from a closed economy to an open economy has on the optimal level of IP protection in the domestic country under the three possible regimes: standardization, cooperative decentralization, and non-cooperative decentralization. To answer this question some additional structure is needed. The key question concerns the effect of market size on the optimal IP protection.

Consider first the case of standardization. One way of approaching this question is to consider what would happen if the foreign country were identical to the domestic country except that it did not have an innovating firm. In this case the marginal cost in lost consumer surplus when $\alpha$ is increased is twice as large as in the closed economy case. This, in itself, would tend to reduce the optimal level of $\alpha$. However, the profitability gains associated with increasing $\alpha$ would also rise. Possibly the profitability effects and the consumer surplus effects would exactly match. This is, however, unlikely. If the effect of investment on innovation contains diminishing returns then doubling investment does not double the associated benefit. The consumer surplus effect, on the other hand, does not contain any diminishing returns. Adding the second country strictly doubles the consumer surplus associated with a particular innovation and price configuration. Under these circumstances, moving to an open economy would imply a lower level of IP protection under standardization.

\section{Strategic Trade Policy}

Strategic trade policy focuses on the use of trade policy instruments to shift profits or, more broadly, any economic rents from one country to another by altering the strategic relationships among imperfectly competitive firms. The first paper to analyze this idea formally was Brander and Spencer (1981), and much of the literature is reviewed in Brander (1995). Many trade policy tools have been considered as instruments of strategic trade policy, most obviously tariffs, quotas and subsidies. See Hwang and Mai (1988) for a comparison of tariffs and quotas, and see Ishikawa (1994) for an analysis of a range of policies. However, it is clear that IP policies can also be used as strategic trade policy tools (as noted in Taylor (1993) and elsewhere) but this point has received relatively little attention. There is a small amount of literature that assesses how strategic trade policies (particularly R\&D subsidies) might be affected by variations in IPRs, as in Zigic (2000), but there is little work that seeks 
to interpret recent changes in the international IP regime as reflecting strategic trade policy incentives.

IP policies have important effects on relationships among firms under conditions of imperfect competition, and these effects can lead to large rent transfers across countries. The most obvious point is that increases in IP protection tend to shift profits from potential competitors, potential licensees, and from consumers to innovating firms (or at least to firms that acquire the associated IPRs). This comes about in part by restricting entry of rivals and by conditioning the terms on which licenses might be granted. One particularly interesting phenomenon is "cross-licensing" or "patent pools". A less flattering term would be "patent cartels". A patent pool consists of an agreement by a group of firms to use each other's patents (or some of each other's patents) freely or at a nominal license fee. Such agreements are helpful or even essential in view of the large numbers of patents potentially involved in some production processes. These agreements occur disproportionately among large innovators in the US. One effect of such arrangements is to make it very difficult for other potential competitor firms to enter the affected markets.

In many circumstances it could be thought that strategic trade policy effects are incidental effects of policy - not intended by policy makers. However, many US policy makers and politicians have been clear about their intent to increase the profitability of large US-based firms seeking strong intellectual property rights. This paper suggests that increasing the length of patents, increasing the ease with which patents can be obtained, increasing the ability to gain financial compensation, and imposing increased enforcement requirements through TRIPs can all be given a clear strategic trade policy interpretation.

The simple formal model set out so far does not contain explicit imperfectly competitive rivalries between firms and therefore does not explicitly demonstrate strategic trade policy incentives. However, to the extent that $\alpha$ reflects the ease with which potential competition might enter the market it does condition potential strategic rivalries between such entrants and the monopoly innovator and therefore does implicitly touch on strategic trade policy issues. More importantly, as in strategic trade policy, the model presented so far places emphasis on shifting rents between countries.

This subsection provides an extension of the basic model to incorporate explicit strategic trade policy considerations. To keep things as simple as possible, a "thirdmarket" model is considered. There are two countries ( $A$ and $B$ ) that might potentially produce a product and a third country that consumes the product. Country $A$ contains an innovative firm, referred to as firm $A$. Country $B$ contains a potential rival that might, depending on the IP regime, either imitate the innovation of firm $A$, license the innovation from firm $A$, or be precluded from the market.

Consider a 3 -stage game. In stage 1 the governments in countries $A$ and $B$ determine the level of IP protection. This might be done non-cooperatively or it might be done by agreement. Stage 1 determines the license fee to be paid by firm $B$ for the innovation. A sufficiently high license fee prevents entry by firm $A$. A license fee of 0 is possible, implying no IP protection. Thus all three possibilities (exclusion, active licensing, or free imitation) can be nested in this choice of the license fee, $f$, to be paid by firm $B$.

In stage 2 , firm $A$ chooses its investment in innovation. In stage 3 , firms $A$ and $B$ decide how much output to produce in the third market. To keep things as simple as possible, I abstract from consumption in countries $A$ and $B$. (Adding such consumption does not change the basic insights.) Firms $A$ and $B$ interact as rivals in the third market. 
It is assumed that firms $A$ and $B$ would produce a new (i.e. innovative) homogenous product. The amount of innovative investment (or R\&D) undertaken by firm $A$ (and denoted $I$ ) determines the marginal cost of production. Consider stage 3 first. The stage 3 profit functions can be written as follows.

$$
\begin{aligned}
& \pi^{A}=p q^{A}-c(I) q^{A}+f q^{B}-I \\
& \pi^{B}=p q^{B}-c(I) q^{B}-f q^{B}
\end{aligned}
$$

The profit function for firm $A$ includes sunk innovation cost $I$. This cost is incurred in stage 2 and therefore cannot be changed once stage 3 is reached. License fee $f$ is determined in stage 1 and is therefore also pre-determined once stage 3 is reached. The structure of this problem is similar to Spencer and Brander (1983), who consider a 3-stage duopoly game consisting of government subsidy choices in stage 1, firm-level R\&D choices in stage 2, and output choices (in a Cournot model) in stage 3. In that model, as in the model suggested here, in stage 3 , the outputs and profits of the two firms are determined by the marginal costs of production, which depend on $I$, and by the license fee. The following can be written:

$$
\pi^{A}=\pi^{A}(c(I), f) ; \pi^{B}=\pi^{B}(c(I), f) .
$$

It is clear from this structure that $\pi^{A}$ is increasing in $f$ and $\pi^{B}$ is decreasing in $f$. This occurs because $f$ represents a direct transfer from firm $A$ to firm $B$. Also, the effective marginal cost is the marginal cost of production plus the license fee, $f$, for firm $B$, implying that $f$ conditions the rivalry between the two firms. Provided $p-c>f$, firm $A$ prefers to produce and sell a unit itself to having firm $B$ make the sale.

In stage 2 , firm $A$ determines its innovation investment $I$. It might decide $I=0$, in which case no investment occurs and the product is not sold. If so, the return to each firm and to each country is 0 . The higher the level of $f$, the more attractive the situation is to firm $A$. It would like a level of $f$ that is sufficiently high so as to preclude entry by firm $B$ altogether, in which case it could act as a monopolist. There is some critical value of $f$ (which might be zero or might be strictly positive) that will just be sufficient to induce innovation by firm $A$. In stage 1 , license fee $f$ is determined. One possibility is that it is determined unilaterally by government $B$. If so, then depending on the details of demand and cost, it is possible that government $B$ might set the license fee to 0 (i.e. opt for no IP protection). However, it might also favor a positive license fee if such a fee is necessary to induce firm $A$ to enter the market.

In this stark model, IP policy objectives in the two producing countries are driven entirely by profit-shifting (i.e. by strategic trade policy) considerations. If consumption in countries $A$ and $B$ is introduced, then profit shifting objectives will still be present, although efficiency-based considerations arising from consideration of consumer welfare will be relevant. If such consumption is considered, it follows that, under segmented markets, the efficient license fee is different in each market. In any case, this discussion makes the rent-shifting strategic trade policy incentives associated with IP protection clear.

In addition to starkly illustrating the strategic profit-shifting aspect of intellectual property policy, the third market model described here also emphasizes the coincidence 
of interests between the imitating country and the consuming country. The consuming country would, like country $B$, favor a relatively weak IP regime, provided there was enough IP protection to generate the innovation. The innovating country has an incentive to favor additional IP protection (i.e. a higher license fee), beyond the level preferred by the other countries and above the level that would maximize world welfare.

\section{Empirical Analysis of International IP Protection}

Much of the debate over the appropriate role of level and structure of international IP protection rests on empirical judgments. As indicated in Section 2, it seems clear that we would expect the increases in IP protection associated with TRIPs to have redistributional effects that would favor the United States and (possibly) other exporters of intellectual property at the expense of importers of IP. This is consistent with a "rent-shifting" or strategic trade policy interpretation of TRIPs. As the IP exporters are, in general, much better off than the IP importers, this redistribution would be regressive. However, an important question concerns the size of these rent-shifting effects, which might be related to total patent-related activity. Figure 2 shows the stunning growth in US patents granted over the past few decades.

Figure 2: US patent applications and grants 1950-2006

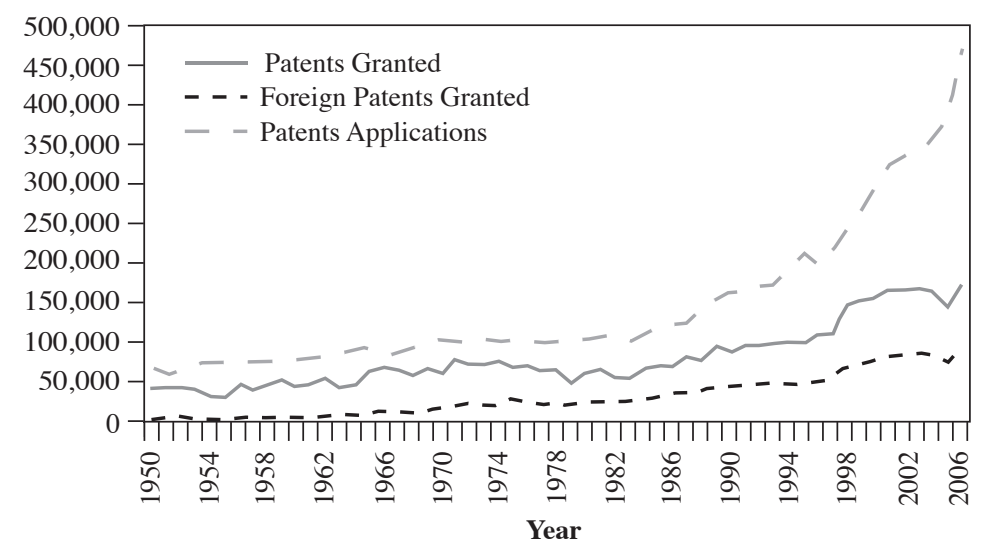

Source: US Patent and Trademark Office, accessed on-line May 2007, http://www.uspto.gov.

Figure 2 shows that US patents have been sought much more aggressively in recent years than even a decade or two ago, particularly since TRIPs went into effect in 1995. Patent litigation has also grown enormously. As noted in Cook (2005), the number of patent lawsuits filed in US federal courts rose from about 60,000 in 1980 to over 180,000 in 2000 . In fact, the growth of lawsuits was approximately proportional to the growth of patents. Jaffe and Lerner (2004) suggest that many patents are obtained primarily as ammunition for litigation rather than because of any clear link to technological innovation. 
It is possible that the great increase in patent activity (including applications, grants and litigation) reflects increases in innovation rather than increases in rent-seeking. If so, it might be expected that productivity changes would show some response to any such increase in innovation. Figure 3 shows US labor productivity changes from 1950 through 2006.

Figure 3: US labor productivity growth 1950-2006 (annual change in percent)

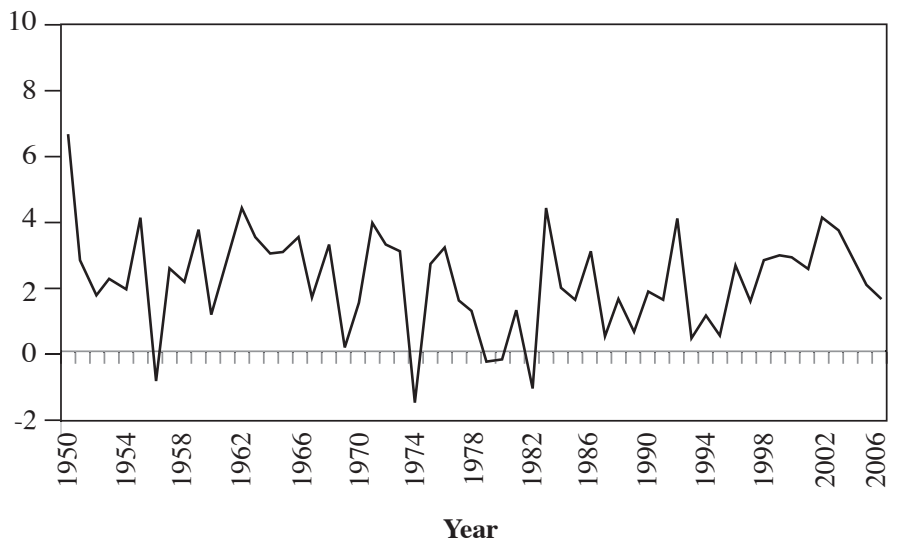

Source: US Bureau of Labor Statistics, on-line as of May 2007, http://www.bls.gov.

As shown in Figure 3, the recent dramatic increase in patent activity has no apparent relationship to productivity growth, which has fluctuated in essentially the same range for the past 60 years. The late 1970s and early 1980s were a disappointing period for productivity growth but, apart from that, there has been no notable change over the period shown. The main inference to be drawn from this discussion is that the level of IP protection in the US might have been extended well beyond the efficient level. Possibly it has been extended to the point where it reduces rather than promotes innovation. Similar comments would be applicable to other jurisdictions, such as Europe and Canada.

An assessment of the redistributional effects of TRIPs has been addressed in a valuable paper by McCalman (2001). The data requirements are substantial as we would need to know how valuable the patents (and other protected IP) might turn out to be. McCalman deals with this by posing a hypothetical question. He asks what the effect would have been if TRIPs had been applied to the patents applied for in 1988 . This allows a long enough time period subsequent to 1988 to value these patents. The following table summarizes some of the information in McCalman's Table 4, showing the hypothetical transfers associated with applying TRIPs to 1988 patents. McCalman deals with 28 countries, which have here been combined into the categories shown. (The list of countries is not exhaustive, and the transfers do not sum to zero.) 
Table 1

Hypothetical transfers from applying TRIPs to 1988 patents

\begin{tabular}{ll}
\hline Region & Transfer (1988 \$US millions) \\
\hline United States & 4553 \\
Western Europe* & -357 \\
Latin America** & -1447 \\
Japan and Korea & -765 \\
India & -526 \\
Other*** & -1278 \\
\hline$*$ & Austria, Belgium, France, Germany, Greece, Ireland, Italy, Netherlands, Portugal, Scandinavia, Spain, \\
& Switzerland, UK \\
** & Brazil, Columbia, Mexico, Panama \\
$* * *$ & Australia, Canada, Israel, New Zealand, South Africa
\end{tabular}

Some areas of interest are excluded, including China, Eastern Europe, most of Africa and the Middle East, and much of Latin America. McCalman's analysis incorporates both statistical estimation and calibration, and much of the analysis relies on rough approximation, so it would be a mistake to regard these numbers as precise. However, it is this author's belief that the rough orders of magnitude are likely to be robust and that the overall pattern is instructive. Roughly speaking, the US receives a large transfer and all other regions lose. Some of the individual countries in Western Europe gain, but no country gains as much relative to GDP as the US and no country gains anywhere near what the US gains in absolute terms. All countries aside from the United States and a few European countries lose.

The actual numbers are not large relative to current GDP. However, these numbers reflect only one year's worth of patents, do not include other forms of IP, are denominated in 1988 US dollars, and do not reflect the large increase in patent activity that has taken place subsequent to 1988. Taking these factors into account suggests that the transfers would be significant relative to GDP and possibly substantial.

Redistribution is only part of the story. The other part of the story concerns efficiency. If increasing IP protection has increased efficiency and gives rise to greater economic growth, the effects might swamp any regressive distributional effects. There is a substantial literature on the empirical effects of increased intellectual property protection on variables related to efficiency. Most of this work assesses the effect of IP policy changes on particular variables that are related to overall economic welfare, such as total trade flows, the location and quantity of direct investment, the extent of technology transfer, the level of patent applications, the amount of R\&D activity, etc. However, it is difficult to combine these effects into an overall assessment of the effect of IP protection on aggregate productivity, economic growth, economic efficiency or any other aggregate measure closely related to overall economic welfare.

Before describing specific papers, there are two summary points to consider. First, as previously noted, it might be an oversimplification to treat IP protection as a (onedimensional) scalar variable. There is a literature dealing with the trade-off between different dimensions of IP policy, particularly the trade-off between patent length and 
patent breadth. (See, in particular, Gilbert and Shapiro (1990) and Gallini (1992).) Some extensions of IP protection might enhance efficiency while other expansions might reduce efficiency. To take an arbitrary example, it is possible that enhanced trademark protection might enhance efficiency while enhanced copyright protection might reduce efficiency. However, this author is not aware of any evidence to suggest that this multidimensional aspect of IP protection is a major problem, and therefore this point will not be pursued further.

Second, efficiency and economic welfare more broadly are not likely to be monotonically increasing in IP protection. Presumably small amounts of IP protection are efficiency-enhancing while sufficiently high levels of IP protection would harm economic welfare, as compliance costs, market power inefficiencies, and other costs would more than offset any benefits. Therefore, when the empirical evidence is considered, it should be kept in mind that a particular episode of IP enhancement in a particular jurisdiction might be efficient, but it does not follow that further strengthening of IP protection at present in countries like the US would enhance efficiency.

One recent paper addressing the effect of increased IP protection is Branstetter, Fisman, and Foley (2006). This paper uses US data to estimate the effect of increased IP protection on technology transfer between US parent firms and affiliates in other countries. As a proxy for technology transfer the authors use expenditure on $R \& D$ and royalty payments. They find that when IP protection is increased in a specific country, such expenditures and payments increase markedly in that country among affiliates of US companies that use US patents extensively. In other words, the inference to be drawn is that when a given country strengthens its IP protection, firms that might be expected to have high potential for innovation (affiliates of US-based patent intensive multinationals) do in fact undertake more R\&D and draw more heavily on technology transfer than other firms.

On the other hand, in related work, Sakakibara and Branstetter (2001) test whether strengthened IP protection created by the Japanese patent reforms of 1988 increased innovation. They find that the Japanese patent reforms of 1988 "significantly expanded the scope of patent rights" but that this did not result in an increase in either R\&D spending or innovative output. Similarly, Scherer and Weisburst (1995) and Lerner (2002) find no effect of strengthened IP rights on innovation while Chen and Puttitanum (2005) do find such an effect. Jaffe and Lerner (2004) argue that recent expansions of IP protection have negative effects on innovation, as do Murray and Stern (2007). It would be expected that, if enhanced IP protection was to improve economic welfare, one essential mechanism would be a positive effect of IP protection on innovation. The fact that the record is at best mixed makes the link between enhanced IP protection and efficiency gains problematic.

Similarly, if enhanced IP protection is to provide efficiency gains, one might expect these gains to be realized in part through trade flows and through increased investment flows. Maskus and Penubarti (1995) and Smith (2001) suggest that enhanced IP protection increases trade. On the other hand, Maskus and Eby-Konan (1994) find no effect of increased IP protection on foreign direct investment. Of very direct relevance to the international questions raised here is Qiu and Yu (2007), who ask whether increases in non-US IP protection arising from TRIPs have stimulated innovation in the US Their results are mixed and the following is from the final sentence of their abstract: "This result [suggests that] .... further strengthening foreign patent protection simply increases the US innovators' rent, but not their innovation." 
This brief review of empirical work on the efficiency effects of IP policy changes is far from comprehensive. However, it should be sufficient to indicate that, while valuable work has been done, such work is still in its early stages and there are few if any consensus regularities in the data. My own reading of the empirical evidence is consistent with that of Jaffe and Lerner (2004) and Murray and Stern (2007). If anything, it seems that recent expansions of IP protection in jurisdictions like the United States have probably reduced innovation and reduced efficiency. The case regarding IP policy changes in low income countries such as China, India, and Latin America is less clear. Possibly the current level of IP protection is low enough in such countries that increases might cause efficiency gains. However, if there is a positive effect of recent IP rights enhancement (including TRIPs), the effect is notably elusive.

\section{Concluding Remarks}

This paper assesses the current debate over international protection of IP, including a selective review of recent research. It suggests that there is a tension between academic research and what might be described as the "policy consensus" in major innovationexporting countries. The policy consensus is reflected in the WTO TRIPs agreement that went into effect in 1995 and in the continuing evolution of the international IP policy regime. The two primary features of this policy consensus consist of international standardization - seeking to make IP policies increasingly standardized across countries, and simply increasing the level of IP protection. The TRIPs agreement requires stronger standards and increased enforcement in most signatory countries.

In the US and elsewhere the past two decades have given rise to a dramatic increase in patent applications, patents granted, and in the amount of patent litigation. Copyright and trademark litigation is also sharply higher, and courts have become, on the whole, increasingly sympathetic to IP claims, notwithstanding some very recent US Supreme Court decisions in the other direction. Also, whole new areas of patenting have emerged, including business method patents, software patents, and patents of genetically modified animals.

Given the strength of the movement toward enhanced and standardized IP protection, one might expect a significant body of research supporting such change. However, both the theoretical literature and the empirical records seems to show that the support for such policy positions is equivocal at best. The basic theoretical principles are illustrated by a simple reduced form model provided in Section 4 . These insights suggest that an increasingly open world economy should, if anything, give rise to reduced IP protection in innovation exporters like the US. Furthermore, the analysis in this paper suggests that considerable variation across countries rather than standardization would be appropriate from a normative point of view.

At the empirical level, it seems clear that the transfers associated with IP protection are large and regressive, in the sense that the flow is from low income countries toward high income countries - primarily to the US. One plausible conclusion is that the current international IP standards are, in effect, a type of strategic trade policy whose main effect is to transfer rents rather to enhance innovation or economic efficiency. The efficiency benefits, if any, of enhanced international IP protection are hard to identify. The case 
made by Jaffe and Lerner (2004) and by others is that the US has already pushed IP protection beyond the optimum, even from a purely domestic point of view. Arguably, part of the reason for the expansion of IP protection is the "capture hypothesis" as policy authorities seem to be excessively influenced by producer interests.

Intellectual property policy is an important research area. Despite significant contributions to date, our understanding of appropriate IP policy remains very incomplete. At an empirical level, it would be helpful to know more about the consequences of various types of IP policy for innovation, productivity, and economic performance more broadly. At a theoretical level, a strategic trade policy perspective might be a useful addition to our understanding of international protection of intellectual property.

\section{References}

Anton, J.J. and D.A. Yao, 1994, "Expropriation and Inventions: Appropriable Rents in the Absence of Property Rights", American Economic Review 84, 190-209.

Arundel, A. and I. Kabla, 1998, "What Percentage of Innovations are Patented? Empirical Estimates for European Firms", Research Policy 27, 127-141.

Arrow, K.J., 1962, "Economic Welfare and the Allocation of Resources for Invention", in R. Nelson (ed) The Rate and Direction of Inventive Activity (Princeton University Press, Princeton, NJ).

Boldrin, M. and D.K. Levine, 2004, "Rent-seeking and innovation”, Journal of Monetary Economics 51, 127-160.

Brander, J.A., 1995, "Strategic Trade Policy", in G.M. Grossman and K. Rogoff (eds), Handbook of International Economics, Vol. 3, (North-Holland, Amsterdam), $1395-1455$.

Brander, J.A., 2007, “Sustainability: Malthus Revisited?", Canadian Journal of Economics $40,1-38$.

Brander, J.A., E.J. Egan and T.F. Hellmann, 2007, “Government Sponsored Venture Capital in Canada: Effects on Competition, Innovation, and Value Creation", Discussion Paper, University of British Columbia.

Brander, J.A. and B.J. Spencer, 1981, "Tariffs and the Extraction of Foreign Monopoly Rent Under Potential Entry", Canadian Journal of Economics 14, 371-384.

Branstetter, L., R.J. Fisman, and C.F. Foley, 2006, "Do Stronger Intellectual Property Rights Increase International Technology Transfer? Empirical Evidence from US Firm-Level Panel Data”, Quarterly Journal of Economics 121, 321-349.

Chen, Y. and T. Puttitanum, 2005, "Intellectual Property Rights and Innovation in Developing Countries", Journal of Development Economics 78, 474-493.

Chin, J.C., and G.M. Grossman, 1990, "Intellectual Property Rights and North-South Trade", in R.W. Jones and A.O. Kreuger (eds), The Political Economy of NorthSouth Trade: Essays in Honor of Robert E. Baldwin (Basil Blackwell: Cambridge, UK), 90-107.

Cook, J.P., 2005, “On Understanding the Increase in US Patent Litigation”, presented at the 2005 American Law and Economics Association Annual Meeting, Paper 4. Working paper, Berkeley Economic Press law.bepress.com/alea/15th/art4. 
Deardorff, A.V., 1992, "Welfare Benefits of Global Patent Protection", Economica 59, $35-51$.

Denicolò, V., 1996, "Patent Races and Optimal Patent Breadth and Length", Journal of Industrial Economics 44, 249-266.

Diwan, I. and D. Rodrik, 1991, "Patents, Appropriate Technology, and North-South Trade", Journal of International Economics 30, 27-48.

Dunford, R., 1987, “The Suppression of Technology as a Strategy for Controlling Resource Dependence", Administrative Science Quarterly 32, 512-525.

Gallini, N., 1992, "Patent Policy and Costly Imitation", Rand Journal of Economics 23, 52-63.

Gilbert, R. and C. Shapiro, 1990, “Optimal Patent Length and Breadth”, Rand Journal of Economics 21, 106-112.

Grossman, G.M., and E.L. Lai, 2004, "International Protection of Intellectual Property”, American Economic Review 94, 1635-1653.

Harris, C.J. and J. Vickers, 1985, "Patent Races and the Persistence of Monopoly", Journal of Industrial Economics 33, 461-477.

Helpman, E., 1993, “Innovation, Imitation, and Intellectual Property Rights”, Econometrica 61, 1247-1280.

Hwang, H. and C. Mai, 1988, "On the Equivalence of Tariffs and Quotas under Duopoly: A Conjectural Variation Approach", Journal of International Economics 24, 373-380.

Ishikawa, J., 1994, "Ranking Alternative Trade-Restricting Policies Under International Duopoly", Japan and the World Economy 6, 157-169.

Jaffe, A.B. and J. Lerner, 2004, Innovation and Its Discontents: How our Broken Patent System is Endangering Innovation and Progress, and What to do About it (Princeton University Press: Princeton, NJ).

Kortum, S. and J. Lerner, 1999, "Stronger Protection or Technological Revolution: What is Behind the Recent Surge in Patenting?", Carnegie-Rochester Conference Series on Public Policy 48, 247-304.

Lai, E.L. and L.D. Qiu, 2003, “The North's Intellectual Property Rights Standard for the South?", Journal of International Economics 59, 183-209.

Lai, E.L. and L.D. Qiu, 2004, "Protection of Trade for Innovation: The Roles of Northern and Southern Tariffs", Japan and the World Economy 16, 449-470.

Lerner, J., 2002, "150 Years of Patent Protection", American Economic Review Papers and Proceedings 92, 221-225.

Loury, G., 1979, "Market Structure and Innovation”, Quarterly Journal of Economics 93, 395-410.

Maskus, K.E. and D. Eby-Konan, 1994, “Trade-Related Intellectual Property Rights: Issues and Exploratory Results", in A. Deardorff and R.M. Stern (eds), Analytical and Negotiating Issues in the Global Trading System (University of Michigan Press: Ann Arbor, MI).

Maskus, K.E. and M. Penubarti, 1995, "How Trade-related are Intellectual Property Rights?", Journal of International Economics 39, 227-248.

McCalman, P., 2001, "Reaping What You Sow: An Empirical Analysis of International Patent Harmonization”, Journal of International Economics 55, 161-186. 
McCalman, P., 2005, "Who enjoys 'TRIPs' Abroad? An Empirical Analysis of Intellectual Property Rights in the Uruguay Round", Canadian Journal of Economics $38,574-603$.

Murray, F., and S. Stern, 2007, "Do Formal Intellectual Property Rights Hinder the Free Flow of Scientific Knowledge? An Empirical Test of the Anti-Commons Hypothesis", Journal of Economic Behavior and Organization 63, 648-687.

Nordhaus, W.D., 1969, Invention Growth, and Welfare: A Theoretical Treatment of Technological Change (MIT Press, Cambridge, MA).

Nordhaus, W.D., 1972, "The Optimal Life of the Patent: Reply", American Economic Review 62, 428-431.

Qiu, L.D. and H. Yu, 2007, "Does the Protection of Foreign Intellectual Property Rights Stimulate Innovation in the US?", Discussion Paper, Hong Kong University of Science and Technology.

Reinganum J.F, 1982, "A Dynamic Game of R\&D: Patent Protection and Competitive Behavior", Econometrica 50, 671-688.

Sakakibara M. and L. Branstetter, 2001, "Do Stronger Patents Induce more Innovation? Evidence from the 1988 Japanese Patent Law Reforms", Rand Journal of Economics $32,77-101$.

Scherer, F.M., 1972, “Nordhaus' Theory of Optimal Patent Life: A Geometrical Reinterpretation", American Economic Review 62, 422-427.

Scherer, F.M., and S. Weisburst, 1995, "Economic Effects of Strengthening Pharmaceutical Patent Protection in Italy", International Review of Industrial Property and Copyright Law 6, 1009-1024.

Scotchmer, S., 2004, Innovation and Incentives (MIT Press, Cambridge, MA).

Smith, P.J., 2001, "How Do Foreign Patent Rights Affect U.S. Exports, Affiliate Sales, and Licenses?" Journal of International Economics 55, 411-439.

Spencer, B.J. and J.A. Brander, 1983, "International R\&D Rivalry and Industrial Strategy", Review of Economic Studies 50, 707-722.

Stigler, G.J., 1971, “The Theory of Economic Regulation”, Bell Journal of Economics 2, 3-21.

Taylor, M.S., 1993, "TRIPS, Trade, and Technology Transfer", Canadian Journal of Economics 26, 625-637.

Tirole, J., 1988, The Theory of Industrial Organization (MIT Press, Cambridge, MA).

Yiannaka, A. and M. Fulton, 2006, "Strategic Patent Breadth and Entry Deterrence with Drastic Product Innovations", International Journal of Industrial Organization 24, 177-202.

Zigic, K., 2000, "Strategic Trade Policy, Intellectual Property Rights Protection, and North-South Trade", Journal of Development Economics 61, 27-60. 